\title{
Multiaxial Low Cycle Fatigue Life of Notched Specimen for Type 316L Stainless Steel under Non-Proportional Loading*
}

\author{
Takamoto $\mathrm{ITOH}^{* *}$, Wei CHEN*** and Ryuta YAMAMOTO*** \\ ${ }^{* *}$ Graduate School of Engineering, University of Fukui \\ 9-1, Bunkyo 3-chome, Fukui-shi, Fukui 910-8507, Japan \\ E-mail: itoh@u-fukui.ac.jp \\ ${ }^{* * *}$ Course of Mechanical Engineering, Graduate School of Engineering, University of Fukui
}

\begin{abstract}
This study discusses multiaxial low cycle fatigue life of notched specimen under proportional and non-proportional loadings at room temperature. Strain controlled multiaxial low cycle fatigue tests were carried out using smooth and circumferentially notched round-bar specimens of type 316L stainless steel. Four kinds of notched specimens were employed with elastic stress concentration factors, $K_{\mathrm{t}}$, as $1.5,2.5,4.2$ and 6.0. The strain paths include proportional and non-proportional loadings. The former employed was a push-pull straining and a reversed torsion straining. The latter was achieved by strain path where axial and shear strains has $90^{\circ}$ phase difference but their amplitudes are the same based on von Mises' criterion. The notch dependency of multiaxial low cycle fatigue life and the life estimation are discussed with employing inelastic finite element analysis. The lives depend on both $K_{\mathrm{t}}$ and strain path. The strain parameter for the life estimation is discussed with the non-proportional strain parameter proposed by an author with introducing $K_{\mathrm{t}}$. The proposed parameter gave a satisfactory evaluation of multiaxial low cycle fatigue life for notched specimen of type $316 \mathrm{~L}$ stainless steel under proportional and non-proportional loadings.
\end{abstract}

Key words: Low Cycle Fatigue, Notch, Life Prediction, Combined Stress, Non-proportional Loading, Finite Element Method, 316L Stainless Steel

\section{Nomenclature}

$f_{\mathrm{NP}} \quad$ Non-proportional factor

$K_{\mathrm{t}} \quad$ Elastic stress concentration factor

$K_{\sigma} \quad$ Stress concentration factor in elastic-plastic regime

$K_{\varepsilon} \quad$ Strain concentration factor in elastic-plastic regime

$N_{\mathrm{f}} \quad$ Number of cycles to failure

$\alpha \quad$ Material constant related to additional hardening due to non-proportional loading

$\varepsilon, \gamma \quad$ Axial total strain, shear total strain

$\Delta \varepsilon_{\mathrm{eq}} \quad$ Equivalent nominal total strain range based on von Mises' criterion

$\Delta \varepsilon_{\mathrm{I}} \quad$ Maximum principal strain range under non-proportional loading

$\Delta \varepsilon_{\mathrm{L}} \quad$ Equivalent local total strain range based on von Mises' criterion

$\Delta \sigma_{\mathrm{eq}} \quad$ Equivalent nominal stress range based on von Mises' criterion

$\Delta \varepsilon_{\mathrm{NP}} \quad$ Non-proportional strain range

$\Delta \varepsilon_{\mathrm{NP}}^{\mathrm{L}} \quad$ Non-proportional strain range evaluated by FEA

$\Delta \sigma_{\mathrm{L}} \quad$ Equivalent local stress range based on von Mises' criterion 


\section{Introduction}

Components and structures like pressure vessels and exchangers often undergo multiaxial low cycle fatigue (LCF) damage. As for the multiaxial LCF under non-proportional loading in which directions of principal stress and strain change in a cycle, it has been reported that obvious life reductions have been observed depending on both strain path and material ${ }^{(1)-(6)}$. Thus, it has been required to develop an appropriate design parameter for multiaxial LCF for the reliable design and maintenance of structural components.

Itoh et al. ${ }^{(4),(5),(7)}$ have carried out a series of multiaxial LCF tests under non-proportional loading with various strain paths in combined axial and shear loadings by using a hollow cylinder specimen, and examined the dependence of the life on strain path and material. They have also proposed a strain parameter for evaluation of multiaxial LCF life under non-proportional loading.

However, few study in multiaxial LCF for notched specimen has been reported. Therefore, this study carried out combined push-pull and reversed torsion multiaxial LCF tests by using smooth and circumferentially notched specimens of type 316L stainless steel under proportional and non-proportional loadings. The notch dependency of multiaxial LCF life was examined and a strain parameter for life estimation is presented.

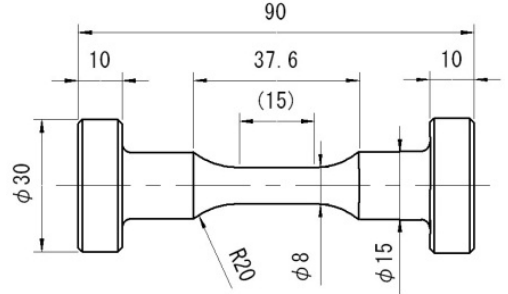

(a) Solid bar smooth specimen $\left(K_{\mathrm{t}}=1\right)$

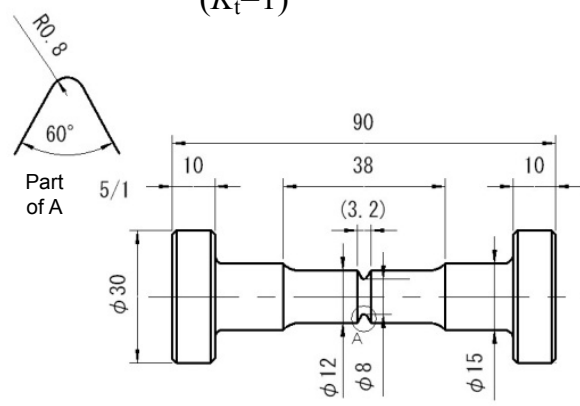

(c) Solid bar circumferentially notched specimen $\left(K_{\mathrm{t}}=2.5\right)$

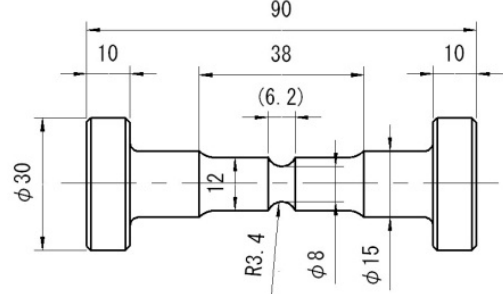

(b) Solid bar circumferentially notched specimen $\left(K_{\mathrm{t}}=1.5\right)$

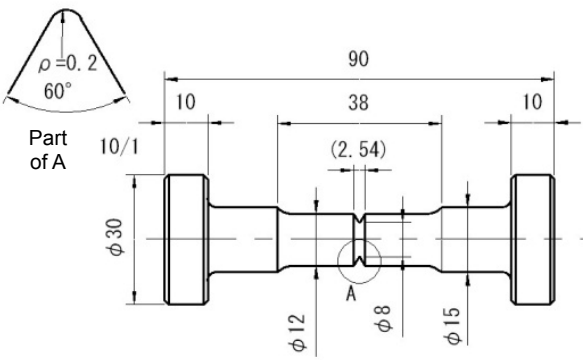

(d) Solid bar circumferentially notched specimen $\left(K_{\mathrm{t}}=4.2\right)$

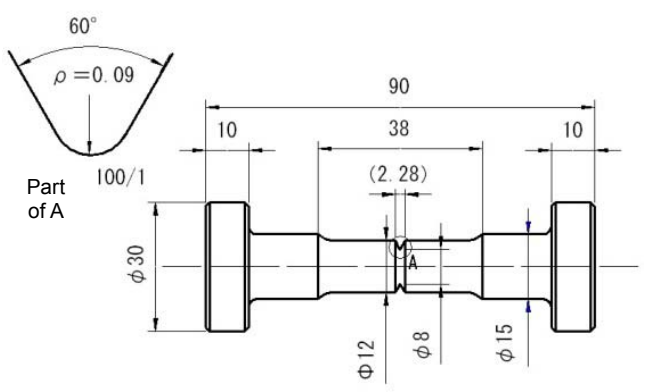

(e) Solid bar circumferentially notched specimen $\left(K_{\mathrm{t}}=6.0\right)$

Fig. 1 Shapes and dimensions of test specimens (mm). 


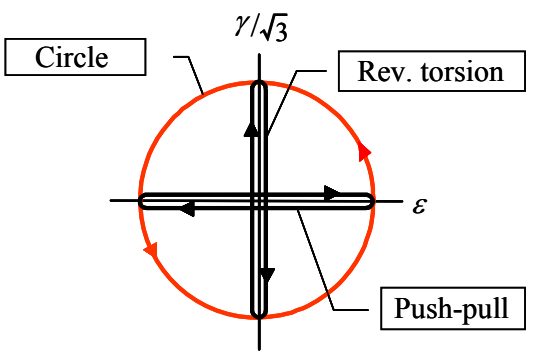

\begin{tabular}{|c|c|c|c|c|c|}
\hline \multirow{2}{*}{ Strain path } & \multicolumn{5}{|c|}{$K_{\mathrm{t}}$} \\
\hline & 1.0 & 1.5 & 2.5 & 4.2 & 6.0 \\
\hline Push-pull & $\square$ & $\bar{\square}$ & 回 & $\square$ & 回 \\
\hline Rev. torsion & $\Delta$ & $\Delta$ & $\Delta$ & $\Delta$ & $\Delta$ \\
\hline Circle & 0 & 0 & (2) & 0 & (1) \\
\hline
\end{tabular}

Fig. 2 Strain paths employed and symbols used in following figures.

\section{Experimental Procedure}

Material tested was the type 316L stainless steel (SUS316L). Specimens used were a smooth solid bar specimen and circumferentially notched solid bar specimens of which elastic stress concentration factor, $K_{\mathrm{t}}$ were $1.5,2.5,4.2$ and $6.0^{(8)}$. Shapes and dimensions of the specimens employed are shown in Fig. 1 (a)-(e). No heat treatment was applied to the specimen after machining.

Total strain controlled multiaxial LCF tests were carried out at room temperature under 3 types of strain paths. The strain paths employed are shown on $\varepsilon-\gamma / \sqrt{3}$ plot in Fig. 2, where $\varepsilon$ and $\gamma$ are axial and shear total strains. Push-pull is the axial tension and compression test, Rev. torsion the revised pure torsion test and Circle the circular loading test which has $90^{\circ}$ phase difference between $\varepsilon$ and $\gamma$. Push-pull and Rev. torsion are proportional loading tests and Circle is the non-proportional loading test where the principal directions are rotated in a cycle. Total strain ranges were the same ranges in all the tests and strain rate was $0.1 \% / \mathrm{sec}$ based on Mises basis.

In Fig. 2, the attached table shows symbols used in figures hereafter for each strain path and for the various $K_{\mathrm{t}}$. In the reversed torsion loading, the elastic shear stress concentration factors of notched specimens for $K_{\mathrm{t}}=1.5,2.5,4.2$ and 6.0 become $K_{\mathrm{s}}=1.17,1.55,1.87$ and 1.96 , respectively ${ }^{(8)}$.

Equivalent nominal total strain range based on von Mises' criterion (Mises' strain range) employed in this study was unique as $\Delta \varepsilon_{\mathrm{eq}}=0.7 \%$. The gage length for measuring axial and shear displacements by a extensometer was $7 \mathrm{~mm}$ for all types of specimens. Number of cycles to failure (failure life), $N_{\mathrm{f}}$, was defined as the cycle at which the stress amplitude decreased to $3 / 4$ of the maximum value. Axial stress amplitude was employed in Push-pull and Circle and shear stress amplitude in Rev. torsion for the judgment of $N_{\mathrm{f}}$.

\section{Results and Discussion}

\subsection{Low Cycle Fatigue Life under Non-proportional Loadings}

Table 1 shows test results. In the table, $\Delta \sigma$ and $\Delta \tau$ are nominal axial and nominal shear stresses at a half cycle of $N_{\mathrm{f}}$. In the Rev. torsion test of $K_{\mathrm{t}}=1$, the specimen did not reach to the failure life over than 100,000 cycles, the test was interrupted at 135,000 cycles. The shear stresses were evaluated from the torque in experiment by assuming the stress and strain relationship to be elastic, so the shear stresses shown in the table may be larger than actual ones.

Figure 3 shows a comparison of $N_{\mathrm{f}}$ in each test at the same strain range, $\Delta \varepsilon_{\mathrm{eq}}=0.7 \%$. In push-pull test, $N_{\mathrm{f}}$ decreases with increasing $K_{\mathrm{t}}, N_{\mathrm{f}}$ in $K_{\mathrm{t}}=6.0$ becomes approximately $6 \%$ of that in $K_{\mathrm{t}}=1.0$. The same trend can be seen in Rev. torsion. However, in Circle, $N_{\mathrm{f}}$ at $K_{\mathrm{t}}=1.5$ is slightly longer than that of the smooth specimen but $N_{\mathrm{f}}$ decreases with increasing $K_{\mathrm{t}}$ in $K_{\mathrm{t}}=2.5-6.0$. The longer life shown in $K_{\mathrm{t}}=1.5$ of Circle may result from the additional hardening reducing the strain amplitude at notch part. Stainless steels are known as 
Table 1 Multiaxial LCF lives of smooth and notched specimens, $\Delta \varepsilon_{\mathrm{eq}}=0.7 \%$.

\begin{tabular}{|c|c|c|c|c|}
\hline \multirow{2}{*}{$\begin{array}{l}\text { Strain } \\
\text { path }\end{array}$} & \multirow{2}{*}{$\begin{array}{c}\text { Stress } \\
\text { concentration } \\
\text { factor } \\
K_{\mathrm{t}}\left(K_{\mathrm{s}}\right)\end{array}$} & \multicolumn{2}{|c|}{$\begin{array}{c}\text { Stress ranges } \\
\text { at } 1 / 2 N_{\mathrm{f}}\end{array}$} & \multirow{2}{*}{$\begin{array}{c}\text { Number of } \\
\text { cycles to } \\
\text { failure } \\
N_{\mathrm{f}} \\
\text { (cycle) }\end{array}$} \\
\hline & & $\begin{array}{c}\Delta \sigma \\
(\mathrm{MPa})\end{array}$ & $\begin{array}{r}\sqrt{3} \Delta \tau \\
(\mathrm{MPa})\end{array}$ & \\
\hline \multirow{5}{*}{$\begin{array}{l}\text { Push } \\
\text {-pull }\end{array}$} & 1.0 & 680 & - & 6,909 \\
\hline & 1.5 & 800 & - & 2,237 \\
\hline & 2.5 & 800 & - & 871 \\
\hline & 4.2 & 810 & - & 571 \\
\hline & 6.0 & 830 & - & 418 \\
\hline \multirow{5}{*}{ Circle } & 1.0 & 780 & 1050 & 2,082 \\
\hline & 1.5 & 850 & 1030 & 2,248 \\
\hline & 2.5 & 880 & 1080 & 475 \\
\hline & 4.2 & 900 & 1140 & 212 \\
\hline & 6.0 & 850 & 930 & 156 \\
\hline \multirow{5}{*}{$\begin{array}{l}\text { Rev. } \\
\text { torsion }\end{array}$} & 1.0 & - & 600 & $>135,000$ \\
\hline & $1.5(1.17)$ & - & 720 & 54,809 \\
\hline & $2.5(1.55)$ & - & 910 & 4,806 \\
\hline & $4.2(1.87)$ & - & 890 & 3,094 \\
\hline & $6.0(1.96)$ & - & 850 & 2,243 \\
\hline
\end{tabular}

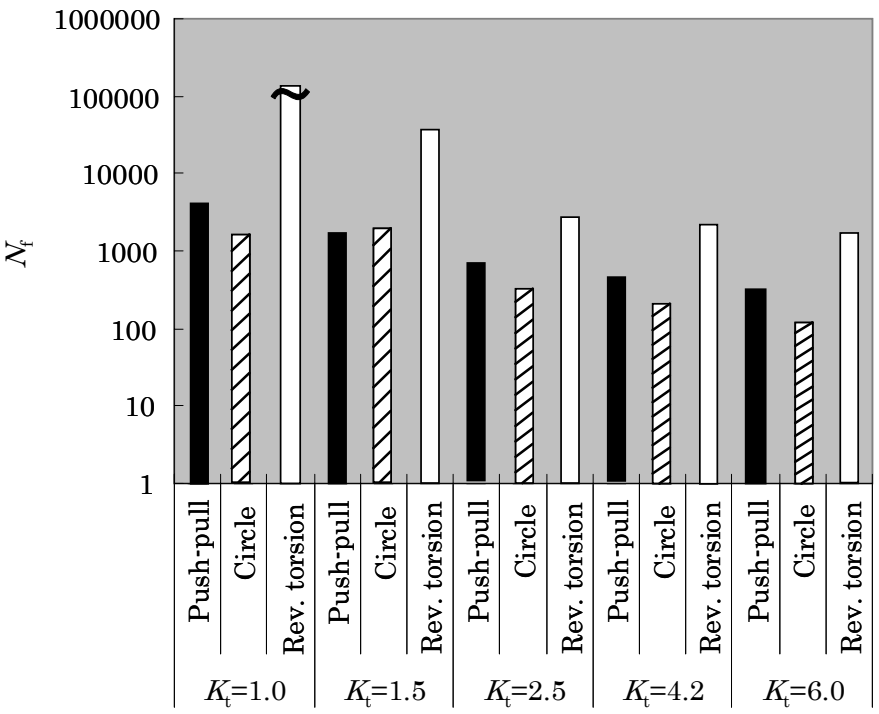

$K_{\mathrm{t}}=1.0$ Push-pull $\forall K_{\mathrm{t}}=1.0$ Circle $\square K_{\mathrm{t}}=1.0$ Rev. torsion - $K_{\mathrm{t}}=1.5$ Push-pull ख $K_{\mathrm{t}}=1.5$ Circle $\square K_{\mathrm{t}}=1.5$ Rev. torsion - $K_{\mathrm{t}}=2.5$ Push-pull $\forall K_{\mathrm{t}}=2.5$ Circle $\square K_{\mathrm{t}}=2.5$ Rev. torsion - $K_{\mathrm{t}}=4.2$ Push-pull $\forall K_{\mathrm{t}}=4.2$ Circle $\square K_{\mathrm{t}}=4.2$ Rev. torsion - $K_{\mathrm{t}}=6.0$ Push-pull 叉K $K_{\mathrm{t}}=6.0$ Circle $\square K_{\mathrm{t}}=6.0$ Rev. torsion

Fig. 3 Comparison of failure lives, $\Delta \varepsilon_{\mathrm{eq}}=0.7 \%$.

materials which show large additional hardening due to non-proportional cyclic loading ${ }^{(2),(4),(6),(9)}$, so the fatigue life in $K_{\mathrm{t}}=1.5$ was influenced by the additional hardening dominantly rather than the stress and strain concentration at the notch root when $K_{\mathrm{t}}$ is small.

The same properties for smooth specimens have been reported in multiaxial LCF studies using hollow cylinder specimens of stainless and carbon steels ${ }^{(9)}$. The similar path dependence of life can be seen in each $K_{\mathrm{t}}$, except the result at $K_{\mathrm{t}}=1.5$ in Circle. The failure lives for SUS316L are affected largely by both the notch and the strain path. 


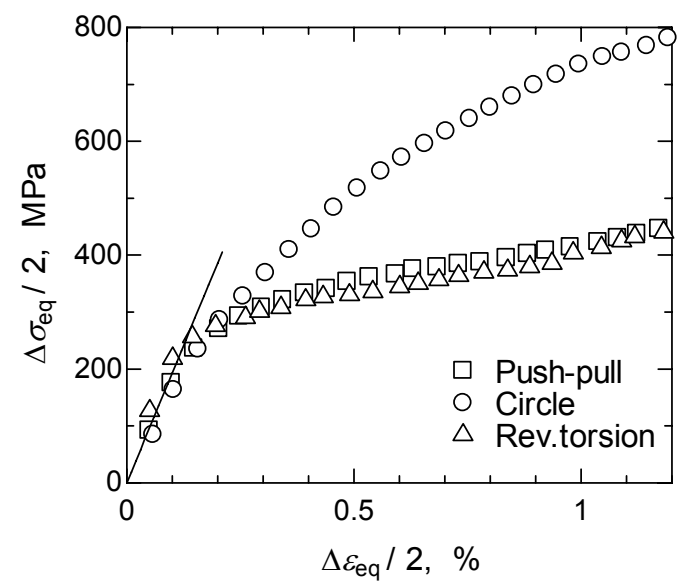

Fig. 4 Cyclic stress-strain relationships.

Figure 4 shows the cyclic stress and strain curve obtained by step-up tests in Push-pull, Circle and Rev. torsion. In these tests, Mises' strain range was increased by $0.1 \%$ at each step (10 cycles). The stress and strain amplitudes plotted in the figure are those at 10th cycle of each step. The cyclic stress and strain curves in Push-pull and Rev. torsion are almost the same on the Mises base, but the curve in Circle shows a large additional hardening due to non-proportional loading obviously.

Figures 5 (a)-(c) are the micro-Vickers hardness measured on cross sections at gauge and notch root parts in Push-pull, Circle and Rev. torsion, respectively. The hardness is the result at cycle $0.3 N_{\mathrm{f}}$ obtained by the interrupted fatigue test. The scale in transverse is distance from surface at the notch root of specimen. In Push-pull, obvious hardening occurs for notched specimens near the notch root. The maximum values of hardness in $K_{\mathrm{t}}=2.5-6.0$ show almost the same level and that in $K_{\mathrm{t}}=1.5$ shows the intermediate level between those of $K_{\mathrm{t}}=1.0$ and $K_{\mathrm{t}}=2.5-6.0$. This result shows that the degree of cyclic hardening increment in the Push-pull test due to notch has a limit around HV200 for SUS316L. The cyclic hardening increment near the notch root in the Circle test can also be seen and the maximum value of hardness is much larger than that in the Push-pull. This result suggests that the additional hardening exists due to non-proportional loading. Moreover, a small cyclic hardening near the notch root can be seen in Rev. torsion.

In summarizing above results, the additional hardening occurs in notched specimen under non-proportional loading depending on both strain path and $K_{\mathrm{t}}$, which may have some effects on lives.

\subsection{Evaluation of Low Cycle Fatigue Life}

It has been reported that multiaxial LCF lives for smooth specimens can be estimated well with energy parameters ${ }^{(4)-(7),(10)}$. The notch root of specimens usually undergoes inelastic condition under LCF. In such a case, a relationship between stress and strain ranges at the notch root and nominal stress and strain ranges is expressed based on the Neuber's rule ${ }^{(11)}$. This study also defines the relationship under multiaxial loading expressed as,

$$
\Delta \sigma_{\mathrm{L}} \Delta \varepsilon_{\mathrm{L}}=\left(K_{\sigma} \Delta \sigma_{\text {eq }}\right)\left(K_{\varepsilon} \Delta \varepsilon_{\text {eq }}\right)=K_{\mathrm{t}}^{2} \Delta \sigma_{\text {eq }} \Delta \varepsilon_{\text {eq }}
$$

where $\Delta \sigma_{\mathrm{L}}$ and $\Delta \varepsilon_{\mathrm{L}}$ are the equivalent local stress and the equivalent local total strain ranges at the notch root based on von Mises' equivalence, respectively. $\Delta \sigma_{\text {eq }}$ and $\Delta \varepsilon_{\text {eq }}$ are the equivalent nominal stress and equivalent nominal total strain ranges based on von Mises' equivalence. $K_{\sigma}$ and $K_{\varepsilon}$ are the stress and strain concentration factors in elastic-plastic regime. 

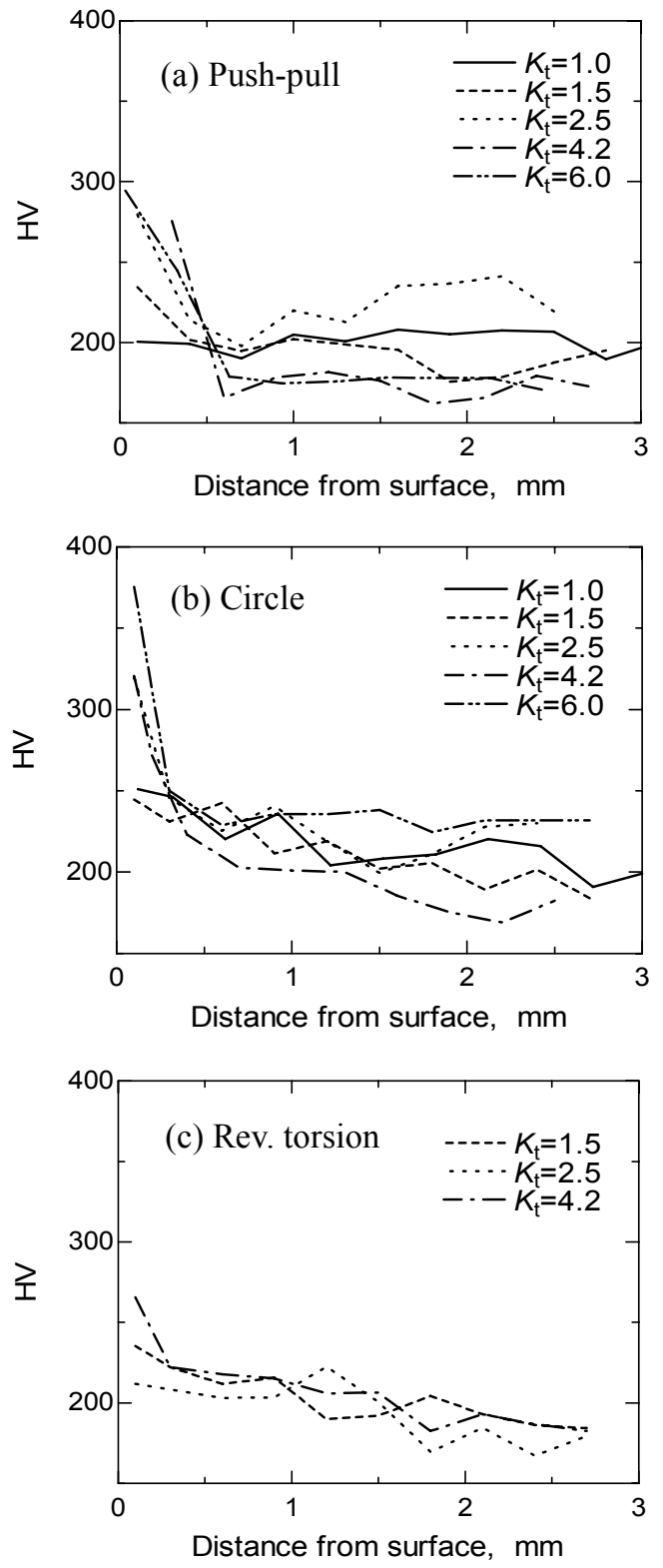

Fig. 5 Hardness on cross section at gauge and notch root parts at each $K_{\mathrm{t}}$, (a) Push-pull, (b) Circle and (c) Rev. torsion.

Evaluation of $N_{\mathrm{f}}$ by the energy parameter, the product of local stress and strain evaluated by $\Delta \sigma_{\text {eq }}$ and $\Delta \varepsilon_{\text {eq }}$ using Eq. (1), is shown in Fig. 6, where $K_{\mathrm{t}}$ takes $K_{\mathrm{s}}$ in Rev. torsion and an averaged value of $K_{\mathrm{s}}$ and $K_{\mathrm{t}}$ in Circle. In the figure, a bold line shows the line based on $N_{\mathrm{f}}$ obtained in the test of Push-pull with smooth specimen $\left(K_{\mathrm{t}}=1\right)$ with referring the data of SUS316NG hollow cylinder smooth specimen tested in the previous author's work ${ }^{(9)}$. Two thinner lines show a factor of 2 band. A large conservative estimation for notched specimens can be seen. The amplitude of local strain is decreased during the test because of large cyclic hardening in SUS316L, so the Neuber's rule tends to overestimate the local strain at notch, resulting in conservative estimation of life as shown in the figure in Push-pull and Circle. Even though Rev. torsion takes a small cyclic hardening which can be expected from the result of hardiness test shown in Fig. 5, $N_{\mathrm{f}}$ in Rev. torsion were also overestimated, which may be resulted from that the local stress was calculated elastically.

As shown in Fig. 6, the additional hardening and the reduction in life are closely related, 


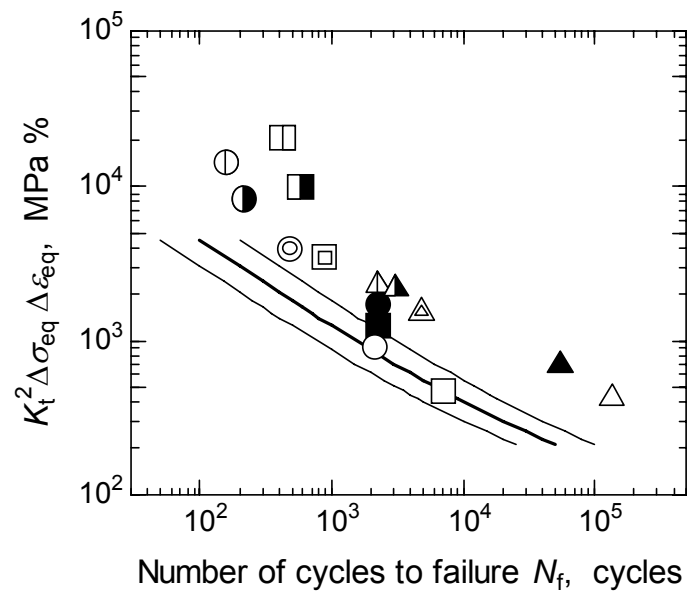

Fig. 6 Correlation of $N_{\mathrm{f}}$ with energy parameter based on Neuber's rule.

which depends on the difference in the deformation behavior due to different crystal structure $^{(12)}$.

Itoh et al. ${ }^{(4),(5),(7)}$ proposed the non-proportional strain range for life evaluation under non-proportional loading equated as,

$$
\Delta \varepsilon_{\mathrm{NP}}=\left(1+\alpha f_{\mathrm{NP}}\right) \Delta \varepsilon_{\mathrm{I}}
$$

where $\Delta \varepsilon_{\mathrm{I}}$ is the maximum principal strain range under non-proportional loading which can be calculated by nominal strains, $\varepsilon$ and $\gamma \cdot \alpha$ and $f_{\mathrm{NP}}$ are the material constant and non-proportional factor, respectively. The former is the parameter related to the additional hardening due to non-proportional loading and the latter is the parameter expressing the intensity of non-proportional loading.

The value of $\alpha$ can be given by two methods ${ }^{(9),(12),(13)}$. One method is to define $\alpha$ as the ratio of stress amplitude in Circle to that in Push-pull by using cyclic stress and strain relationship obtained in the step-up test shown in Fig. 4. The other method is to define $\alpha$ as the strain parameter in Circle to be equivalent to the strain parameter in Push-pull at the same $N_{\mathrm{f}}$ based on life curves obtained in Push-pull and Circle tests. The later method usually gives better correlations of LCF lives of various materials ${ }^{(12)}$. For SUS316L, the two methods evaluate the value of $\alpha$ equivalently as $\alpha=0.9$.

$f_{\mathrm{NP}}$ is defined as,

$$
f_{\mathrm{NP}}=\frac{k}{T \varepsilon_{\mathrm{Imax}}} \int_{0}^{T}\left(|\sin (\xi(t))| \varepsilon_{\mathrm{I}}(t)\right) d t, \quad k=\frac{\pi}{2}
$$

where $T$ is the time for a cycle, $k$ is a constant for making $f_{\mathrm{NP}}=1$ in the circular straining on $\varepsilon-\gamma / \sqrt{3}$ plot and $k=\pi / 2 . \varepsilon_{\mathrm{I}}(t)$ is the maximum absolute value of principal strain given by $\varepsilon_{\mathrm{I}}(t)=\operatorname{Max}\left[\left|\varepsilon_{1}(t)\right|, \varepsilon_{3}(t)\right]$ and the $\varepsilon_{\mathrm{Imax}}$ is the maximum value of $\varepsilon_{\mathrm{I}}(t)$ in a cycle. In the equation, the angle, $\xi(t) / 2$, is employed in order to describe the rotation of principal strain direction. Then, $\xi(t)$ is the angle between $\varepsilon_{\text {Imax }}$ and $\varepsilon_{\mathrm{I}}(t)$ and has double amplitude compared with that in the specimen. The integrand measures the rotation of the maximum principal strain direction and the integration of the strain amplitude after the rotation. Therefore, $f_{\mathrm{NP}}$ totally evaluates the severity of non-proportional straining in a cycle. In this study, the values in Push-pull and Rev. torsion for proportional loading take 0 and that in Circle takes 1 . The non-proportional strain range can correlate LCF lives of smooth hollow cylinder specimen under various non-proportional strain paths $\left(0 \leq f_{\mathrm{NP}} \leq 1\right)$ for different materials under non-proportional loadings ${ }^{(7),(9),(12),(13)}$. The detailed description of the non-proportional strain 
range and the data correlations can be referred to author's previous works ${ }^{(4),(5),(7)}$.

In order to evaluate the local strain based on $\Delta \varepsilon_{\mathrm{NP}}$, this study employs a simple equation equated as,

$$
K_{\mathrm{t}} \Delta \varepsilon_{\mathrm{NP}}=K_{\mathrm{t}}\left(1+\alpha f_{\mathrm{NP}}\right) \Delta \varepsilon_{\mathrm{I}}
$$

In Eq. (4), $K_{\mathrm{t}}$ is employed conventionally. Evaluation of local stress and strain usually requires a complicate procedure such as a finite element analysis (FEA) with taking account of the non-proportional loading effect ${ }^{(14),(15)}$. Actually, cyclic stress-strain relation depends on strain path $\left(f_{\mathrm{NP}}\right)$, material $(\alpha)$ and $K_{\mathrm{t}}$ as shown in Fig. 4 , and then different constitutive relations must be used in FEA in accordance with strain path. Therefore, an assessment of $K_{\sigma}$ and $K_{\varepsilon}$ in elastic-plastic regime under non-proportional loading must need more efforts accompanied by additional experimental tests and discussion.

Figure 7 (a) shows a relationship between $K_{\mathrm{t}} \Delta \varepsilon_{\mathrm{NP}}$ and $N_{\mathrm{f}}$, where $K_{\mathrm{s}}$ was used for $K_{\mathrm{t}}$ in Rev. torsion and $1 / 2\left(K_{\mathrm{s}}+K_{\mathrm{t}}\right)$ in Circle. The overestimation of life shown in Fig. 6 is much improved in the correlation shown in Fig. 7 (a) although $N_{\mathrm{f}}$ at lower strain level in Rev. torsion is still estimated conservatively. Fig. 7 (b) is a life evaluation by the local strain range based on Mises' strain where $\Delta \varepsilon_{\mathrm{I}}$ is replaced by $\Delta \varepsilon_{\text {eq }}$ in Eq. (4). Although comparison

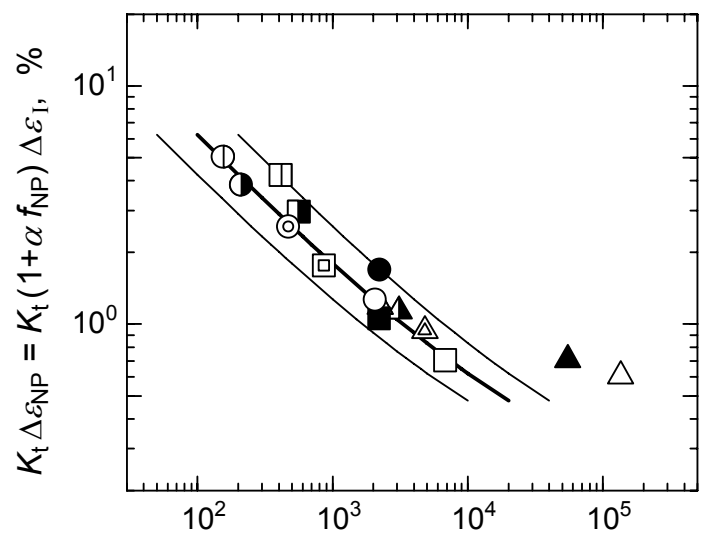

Number of cycles to failure $N_{f}$, cycles

(a) $K_{\mathrm{t}} \Delta \varepsilon_{\mathrm{NP}}$ based on $\Delta \varepsilon_{\mathrm{I}}$

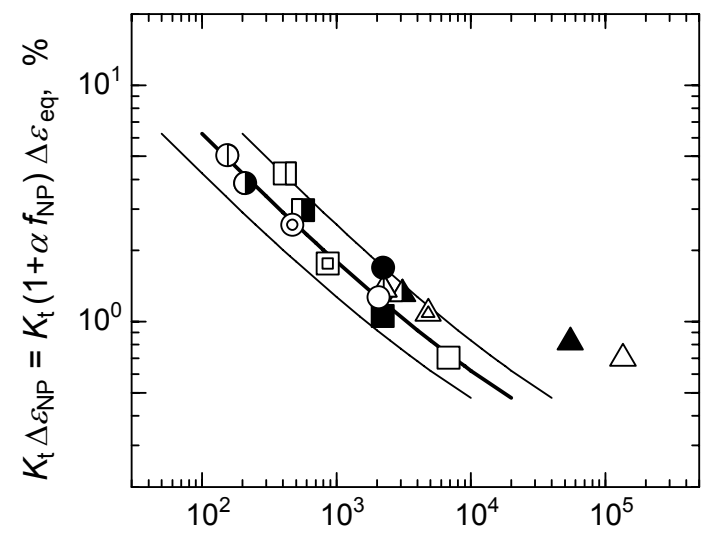

Number of cycles to failure $N_{\mathrm{f}}$, cycles

(b) $K_{\mathrm{t}} \Delta \varepsilon_{\mathrm{NP}}$ based on $\Delta \varepsilon_{\mathrm{eq}}$

Fig. 7 Correlation of $N_{\mathrm{f}}$ with strain parameter based on non-proportional strain range, Eq. (4). 
of data correlations in Figs 7 (a) and (b) shows almost the same trends, a slightly conservative estimation of $N_{\mathrm{f}}$ in Rev. torsion in Fig. 7 (b) can be seen in comparison with that in Fig. 7 (a) which is the smilar trend that has been reported in life evaluation of SUS316L hollow cylinder smooth specimen ${ }^{(12)}$. The corrections in Fig. 7 suggest that $K_{\mathrm{t}} \Delta \varepsilon_{\mathrm{NP}}$ can become an appropriate parameter for life estimation for notched specimens under multiaxial LCF including non-proportional loading.

According to the Neuber's rule, the local strain can be equated as,

$$
\Delta \varepsilon_{\mathrm{eq}}=\frac{1}{K_{\mathrm{t}}^{2}} \frac{\Delta \sigma_{\mathrm{L}}}{\Delta \sigma_{\mathrm{eq}}} \Delta \varepsilon_{\mathrm{L}}
$$

$\Delta \varepsilon_{\mathrm{I}}$ in Eq. (4) is replaced by $\Delta \varepsilon_{\text {eq }}$ in Eq. (5) with assuming $\Delta \varepsilon_{\mathrm{I}}=\Delta \varepsilon_{\mathrm{eq}}$ and then Eq. (4) can be rewritten as,

$$
K_{\mathrm{t}} \Delta \varepsilon_{\mathrm{NP}}=\left(1+\alpha f_{\mathrm{NP}}\right) \frac{\Delta \sigma_{\mathrm{L}} \Delta \varepsilon_{\mathrm{L}}}{K_{\mathrm{t}} \Delta \sigma_{\mathrm{eq}}}
$$

\subsection{Evaluation of LCF Life with FEA}

In order to evaluate $\Delta \sigma_{\mathrm{L}}$ and $\Delta \varepsilon_{\mathrm{L}}$, FEA was performed for each $K_{\mathrm{t}}$ and strain path. FEA code employed was MARC/MENTAT 2008. Elastic-plastic analyses were carried out under axisymmetric 2-dimentional model using an analytical model schematically shown in Fig. 8.

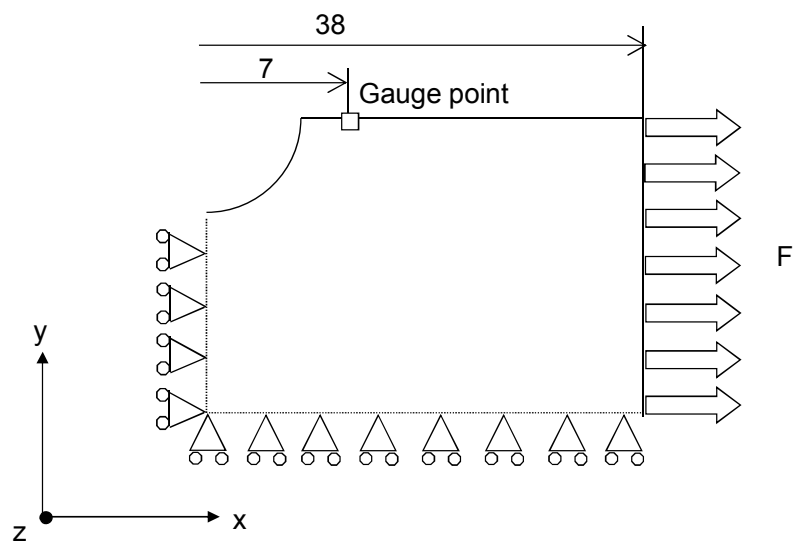

Fig. 8 Schematic showing of FEA model.

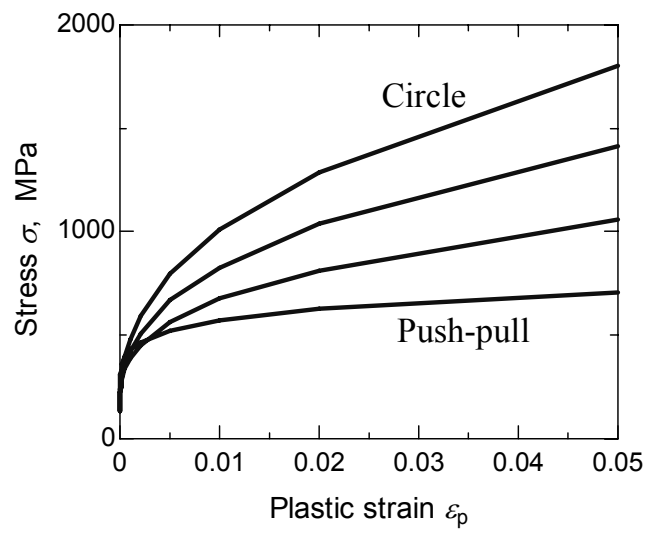

Fig. 9 Constitutive relationships employed in FEA. 


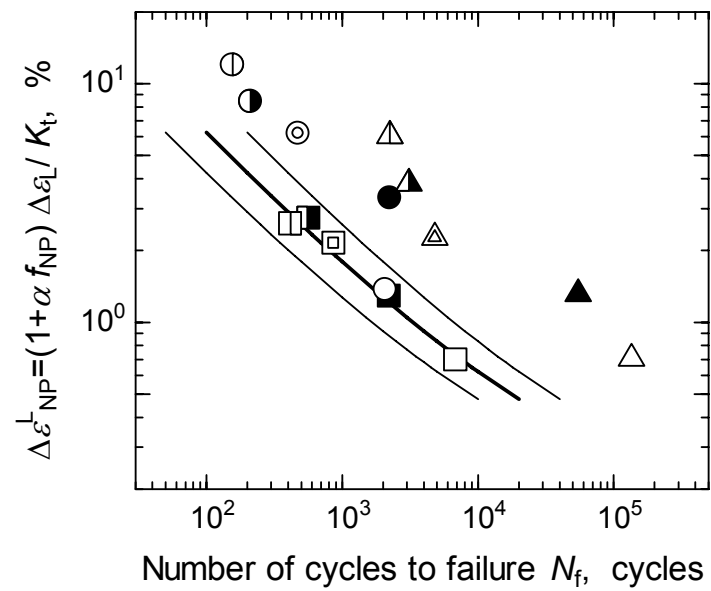

Fig. 10 Correlation of $N_{\mathrm{f}}$ with strain parameter, $\Delta \varepsilon_{\mathrm{NP}}^{\mathrm{L}}$ in Eq. (7).

Constitutive equations used were multi-linear stress-strain curves obtained from push-pull loadings although cyclic stress strain relation may be different depending on strain path as shown in Fig. 9. Cyclic external load $F$ was applied at the edge of the analytical model as a displacement into axial/torsional direction at the gauge point corresponds to the applied strain in experiment. A kinematic hardening rule was used. Stresses and strains at the notch root were obtained from the analytical results at 3 rd cycle.

From FEA and experimental results, $\Delta \sigma_{\mathrm{L}} / \Delta \sigma_{\mathrm{eq}}$ takes 1 approximately in higher strain revel. Thus, Eq. (6) can be rewritten as,

$$
\Delta \varepsilon_{\mathrm{NP}}^{\mathrm{L}}=K_{\mathrm{t}} \Delta \varepsilon_{\mathrm{NP}}=\left(1+\alpha f_{\mathrm{NP}}\right) \frac{\Delta \varepsilon_{\mathrm{L}}}{K_{\mathrm{t}}}
$$

By $\Delta \varepsilon_{\text {NP }}^{\mathrm{L}}$ in Eq. (7) where $\Delta \varepsilon_{\mathrm{L}}$ is obtained by FEA, failure lives are re-plotted in Fig. 10. Although there is a conservative estimation of the data, a relative good correlation of data can be obtained. If $K_{\mathrm{t}}$ was used in Eq. (7) in all the strain paths, correlations of $N_{\mathrm{f}}$ in Rev. torsion and Circle can become better. The result in Fig. 10 suggests that if the local strain range is evaluated analytically using FEA with taking account of path and notch dependencies of life and hardening behaviors, failure lives can be estimated for notched

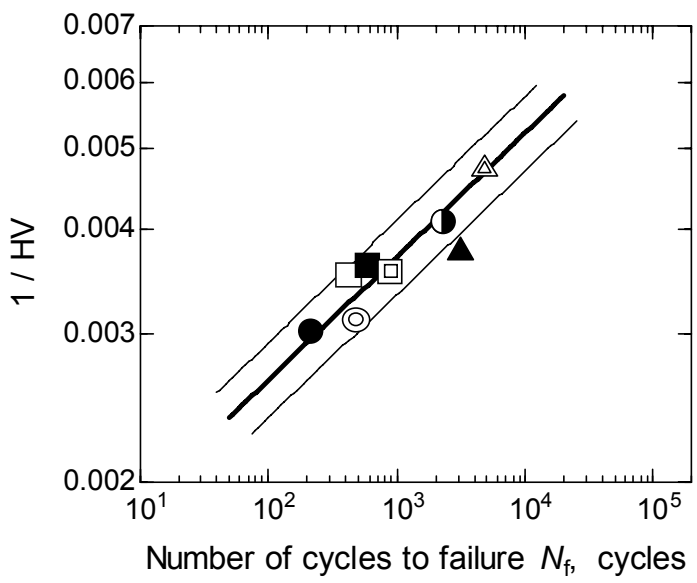

Fig. 11 Relationship between $1 / \mathrm{HV}$ and $N_{\mathrm{f}}$. 
specimen without performing experiment under non-proportional loading. Indeed, as shown in Fig. 11 which shows a relationship between reciprocal values of hardness measured at $0.1 \mathrm{~mm}$ inside from notch root and $N_{\mathrm{f}}$, evaluation of hardening behavior of material at notch root may become a key issue to estimate LCF failure life for notched materials.

\section{Summary}

1. Multiaxial LCF lives for notched specimens depend on both strain path and material tested.

2. The strain parameter for multiaxial LCF life estimation under non-proportional loading for notched specimens is presented based on the non-proportional strain parameter proposed by the author with introducing the stress concentration factor $K_{\mathrm{t}}$.

3. The parameter gives the satisfactory correlation of multiaxial LCF life under proportional and non-proportional loading for the notched specimens of SUS316L.

\section{Acknowledgment}

A part of the present research was conducted as a cooperative work of MF committee in The Japan Welding Engineering Society sponsored by Tokyo Electric Power Company, Hokkaido Electric Power Co. Inc., Tohoku Electric Power Co. Inc., Chubu Electric Power Co., Inc., Hokuriku Electric Power Company, The Kansai Electric Power Co., Inc., The Chugoku Electric Power Co., Inc., Shikoku Electric Power Co. Inc., Kyusyu Electric Power Co., Inc., The Japan Atomic Power Company and Electric Power Development Co., Ltd.

\section{References}

(1) Nitta, A., Ogata, T. and Kuwabara, K., The Effect of Axial-Torsional Straining Phase on Elevated-temperature Biaxial Low-cycle Fatigue Life in SUS304 Stainless Steel, Journal of the Society of Materials Science, Japan, Vol.36 (1989), pp.376-382.

(2) Doong, S.H., Socie, D.F. and Robertson, I.M., Dislocation Substructure and Non-Proportional Hardening, Transaction of the American Society of Mechanical Engineers, Journal of Engineering Materials and Technology, Vol.112, No.4 (1990), pp.456-464.

(3) Wang, C.H. and Brown, M.W., A Path-independent Parameter for Fatigue under Proportional and Non-Proportional Loading, Fatigue \& Fracture of Engineering Materials \& Structures, Vol.16, No.12 (1993), pp.1285-1298.

(4) Itoh, T., Sakane, M., Ohnami, M. and Socie, D.F., Nonproportional Low Cycle Fatigue Criterion for Type 304 Stainless Steel, Transaction of the American Society of Mechanical Engineers, Journal of Engineering Materials and Technology, Vol.117, No.7 (1995), pp.285-292.

(5) Itoh, T., Nakata, T., Sakane, M. and Ohnami, M., Nonproportional Low Cycle Fatigue of 6061 Aluminum Alloy under 14 Strain Paths, European Structural Integrity Society, Vol.25 (1999), pp.41-54.

(6) Socie, D.F. and Marquis, G.B., Multiaxial Fatigue, Society of Automotive Engineers International, (2000), pp.129-339.

(7) Itoh, T., A Model for Evaluation of Low Cycle Fatigue Lives under Nonproportional Straining, Journal of the Society of Materials Science, Japan, Vol.50, No.12 (2001), pp.1317-1322.

(8) Peterson, R.E., Stress Concentration Factor, (1974), p.317, John Wiley and Sons.

(9) Itoh, T., Murashima, K. and Hirai, T., Material Dependence of Multiaxial Low Cycle Fatigue Properties under Non-Proportional Loading, Journal of the Society of 
Materials Science, Japan, Vol.56, No.2 (2007), pp.157-163.

(10) Smith, R.N., Watson, P. and Topper, T.H., A Stress Strain Function for the Fatigue of Materials, Journal of Materials, JMLSA, Vol.5, No.4 (1970), pp.767-778.

(11) Neuber, H., Theory of Stress Concentration for Shear-strained Prismatic Bodies with Arbitrary Nonlinear Stress-strain Law, Trans. ASME, J. Applied Mechanics, Vol.28 (1961), pp.541-550.

(12) Itoh, T. and Yang, T., Material Dependence of Multiaxial Low Cycle Fatigue Lives under Non-Proportional Loading, International Journal of Fatigue, Vol.33, No.8 (2011), pp.1025-1031.

(13) Itoh, T., Sakane, M., Hata, T. and Hamada, N., A Design Procedure for Assessing Low Cycle Fatigue under Proportional and Non-Proportional Loading, International Journal of Fatigue, Vol.28, No.5-6 (2006), pp.495-466.

(14) Li, B., Reis, L. and Freitas, M., Simulation of Cyclic Stress/strain Evolutions for Multiaxial Fatigue Life Prediction, International Journal of Fatigue, Vol.28, No.5-6 (2005), pp.451-458.

(15) Sakane, M. Zhang, S. and Kim, T., Notch Effect on Multiaxial Low Cycle Fatigue, International Journal of Fatigue, Vol.33, No.8 (2011), pp.959-968. 